\title{
CARACTERIZAÇÃO GEOTÉCNICA E CLASSIFICAÇÃO DE SOLOS PARA ESTRADAS FLORESTAIS: ESTUDO DE CASO
}

\author{
GEOTECHNICAL CHARACTERIZATION AND SOILS CLASSIFICATION FOR FOREST \\ ROADS: CASE STUDY
}

\author{
Fabiano Emmert ${ }^{1}$ Reginaldo Sérgio Pereira ${ }^{2}$
}

\begin{abstract}
RESUMO
O estudo teve como objetivo realizar a caracterização geotécnica e a classificação rodoviária para utilização apropriada de diferentes solos locais como materiais de construção de estradas florestais. $\mathrm{O}$ estudo foi realizado em áreas florestais no município de Niquelândia, Goiás, Brasil. Coletaram-se solos finos e granulares predominantes, denominados SL e HA, respectivamente. Os solos foram submetidos a ensaios geotécnicos apropriados para obras rodoviárias, identificando os grupos pertencentes de acordo com as metodologias de classificação TRB e MCT. Os resultados demonstram que o solo SL, com fração predominante de areia fina, possui baixa plasticidade e pertence aos grupos A-4(1) e LA', segundo TRB e MCT, respectivamente. A tensão suportada alcançou $385,10 \mathrm{kPa}$ na maior energia de compactação. A capacidade de suporte foi maior na energia de compactação intermediária. Para o solo granular HA, a fração predominante foi de pedregulho fino e seu enquadramento no grupo TRB foi A-1-b. Segundo a metodologia $\mathrm{MCT}$, o solo SL é material prioritário para base e subleito de estradas. O comportamento esperado para o solo SL é satisfatório como material empregado no subleito, e o HA, excelente, segundo a classificação TRB. A capacidade de suporte dos solos SL e HA indicam que devem ser empregados como reforço de subleito e base, respectivamente. Em estradas florestais, o solo SL pode ser empregado como subleito e HA como base ou revestimento primário.
\end{abstract}

Palavras-chave: caracterização geotécnica de solos; classificação de solos; estradas florestais.

\begin{abstract}
The study aimed to carry out geotechnical characterization and road classification for proper use of different local soils, as construction materials for forest roads. The study was performed in plantation forest areas in the municipality of Niquelândia, Goiás, Brazil. Predominant fine and course soils have been collected, which were called as SL and HA, respectively. Soil samples were submitted to appropriate geotechnical tests for road infrastructures, identifying the pertaining groups in accordance with the methodologies of TRB and MCT classifications. The results demonstrate that SL soil has predominant fraction of fine sand and low plasticity, classified as A-4(1) and LA' groups, in according to TRB and MCT classifications, respectively. The supported tension for this soil reached $385.10 \mathrm{kPa}$ on highest energy of compacting. The highest support capacity was reached on intermediate energy of compacting. For HA soil, the predominant fraction was fine gravel and it has fitted into TRB group as A-1-b soil. According to MCT methodology, SL soil is a priority material for base and subgrade of roads. The expected behavior for SL soil was satisfactory as a useful material for subgrade, whereas HA soil was considered as excellent, both in according to TRB classification. The support capacity of SL and HA soils indicates they must be used as reinforcement of subgrade and base, respectively. For forest roads, SL soil is recommended for subgrade and HA for base or primary layer.
\end{abstract}

Keywords: geotechnical soil characterization; soils classification; forest roads.

1 Engenheiro Florestal, Dr., Bolsista PCI DB/CNPq, Laboratório de Manejo Florestal, Instituto Nacional de Pesquisas da Amazônia, Caixa Postal 478, CEP 69060-020, Manaus (AM), Brasil. fabianoemmert@yahoo.com.br

2 Engenheiro Florestal, Dr., Professor do Departamento de Engenharia Florestal, Faculdade de Tecnologia, Universidade de Brasília, Caixa Postal 4357, CEP 70919-900, Brasília (DF), Brasil. reginaldosp@unb 


\section{INTRODUÇÃO}

As infraestruturas rodoviárias florestais envolvem projetos de engenharia, plantas e mapas, construção e manutenção (SESSIONS, 2007). Um dos principais parâmetros técnicos a ser considerado nos projetos de infraestruturas viárias florestais é o tipo de solo disponível para a construção. Características geotécnicas importantes dos solos utilizados nas estradas florestais podem ser conhecidas em laboratório, realizando as análises de granulometria e limites de consistência (MACHADO; MALINOVSKI, 1986).

A medida do tamanho das partículas constituintes de um solo é feita por meio da análise granulométrica. Amostras de solo são submetidas ao processo de peneiramento em uma série de peneiras padronizadas, separando partículas maiores. Em seguida, o ensaio de sedimentação separa as partículas finas (BUENO; VILAR, 1980).

A consistência define os estados possíveis em que determinado solo pode apresentar em função da umidade. A passagem de um estado para outro não é repentina, mas sim gradual (BUENO; VILAR, 1980). Os limites entre cada estado, definidos em função do teor de umidade, foram empiricamente estabelecidos por Albert Mauritz Atterberg, na Suécia em 1911, e assim foram chamados de limites de Atterberg (KINNISON, 1915; CASAGRANDE, 1932). A mudança de um estado para outro é marcado pelos limites de consistência: limite de liquidez e de plasticidade (CARVALHO, 2004).

Além da granulometria e da consistência dos solos, o conhecimento dos parâmetros de compactação é considerado fundamental para a construção apropriada e respectiva qualidade técnica da estrada. No processo de compactação do solo, as partículas são forçadas a se agruparem mais estreitamente, aumentando a densidade de um solo pelo acúmulo das partículas, reduzindo o seu volume de ar e permanecendo inalterado o seu volume de água (ROAD RESEARCH LABORATORY, 1951; CRAIG, 1980). Os parâmetros de compactação são o peso específico aparente seco máximo $\left(\mathrm{g}_{\text {dmáx }}\right)$ e a umidade ótima $\left(\mathrm{W}_{\mathrm{ot}}\right)$, valores obtidos em ensaios de laboratório (TRINDADE et al., 2008).

A partir dos parâmetros de compactação chega-se ao conhecimento da capacidade de suporte do solo. O potencial do solo do ponto de vista de sua capacidade de sustentação ao tráfego determinado para a estrada é conhecido pelo Índice de Suporte Califórnia-ISC (California Bearing Ratio - CBR).
Baseando-se no valor desse índice, determinase o uso apropriado em camadas de pavimentos (BRASIL, 2006).

Solos diferentes com propriedades similares podem ser classificados em grupos ou subgrupos de acordo com seu comportamento. Os sistemas de classificação fornecem uma linguagem comum para se expressar concisamente, sem descrições detalhadas, as características gerais dos solos, que são infinitamente variadas. Os sistemas de classificação têm o objetivo não só de facilitar os estudos de caracterização, mas, também, antever o comportamento diante das solicitações a que serão submetidos (BUENO; VILAR, 1980; DAS, 2007).

A classificação de solos utilizada na engenharia rodoviária é a classificação HRB (Highway Research Board), proveniente do aperfeiçoamento do antigo sistema da Public Roads Administration. Nesse sistema consideramse a granulometria, o limite de liquidez, o índice de plasticidade e o índice de grupo. Atualmente, o sistema de classificação é denominado de Transportation Research Board - TRB, sendo esse adotado para o caso de estradas florestais (MACHADO; MALINOVSKI, 1986; BRASIL, 2006).

As classificações desenvolvidas para solos de regiões de clima temperado, como o sistema TRB, apresentam limitações e incompatibilidade quando aplicadas aos solos tropicais, devido à natureza e ao comportamento geotécnico diferenciado dos solos formados nessas regiões. Frente às limitações das classificações de solos convencionais em relação aos solos tropicais, a classificação MCT (Miniatura, Compactado, Tropical) foi proposta para determinação das propriedades mecânicas e hidráulicas de solos tropicais compactados para uso em obras viárias (NOGAMI; VILLIBOR, 1981).

Nesse contexto, o objetivo desse estudo foi realizar a caracterização geotécnica e a classificação rodoviária de solos, por meio de experimentação em laboratório, indicando seus potenciais para aplicação em estradas florestais.

\section{MATERIAL E MÉTODOS}

\section{Área de estudo}

O estudo foi realizado em áreas florestais, hortos SL e HA, pertencentes à empresa Anglo American Ltda., coordenadas $14^{\circ} 22^{\prime} 45^{\prime \prime} \mathrm{S}$ e $48^{\circ} 42^{\prime} 32^{\prime} \mathrm{W}$, localizadas no município de 
Niquelândia, Goiás, Brasil (Figura 1). A empresa atua na área de mineração produzindo a liga ferro-níquel, utilizando em parte do processo de beneficiamento do minério, madeira de eucalipto na forma de cavacos.

O clima da região classifica-se como Tropical Brasil Central, quente e semiúmido, com média de temperatura acima de $18^{\circ} \mathrm{C}$ e períodos secos variando de quatro a cinco meses por ano (IBGE, 2002). O solo encontrado na região classifica-se como Latossolo Vermelho Amarelo (EMBRAPA, 2013).

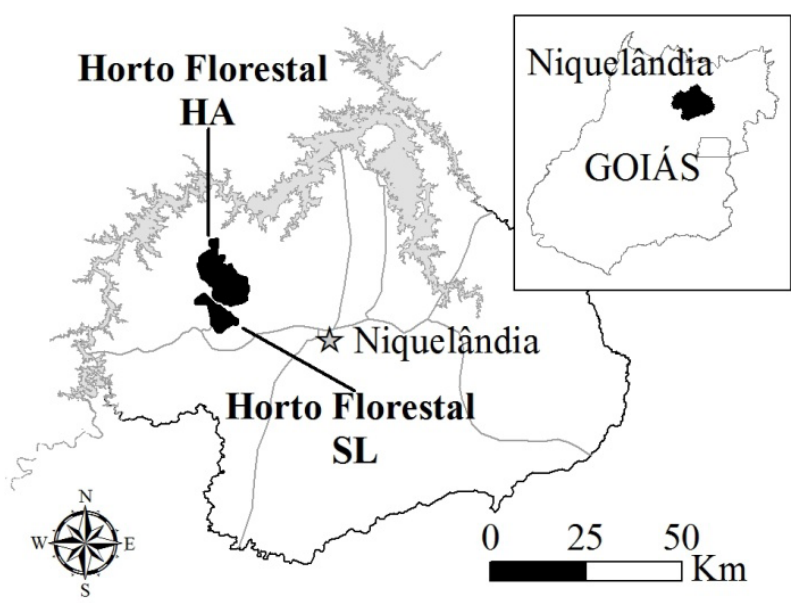

FIGURA 1: Localização da área de estudo, Niquelândia, Goiás.

FIGURE 1: Localization of the area of study, Niquelândia, Goiás.

\section{Coleta de Solos}

No horto SL, foram coletadas amostras em um trecho da estrada florestal principal a cada 50 metros, com pontos de coletas nas laterais e no centro (eixo) da estrada, ou seja, três pontos por amostra (composta). Ao total foram coletadas 19 amostras a profundidade de $20 \mathrm{~cm}$. A área da coleta possui relevo plano. As amostras coletadas nesse local foram denominadas de SL e numeradas conforme a ordem de coleta (SL01 a SL19). Para efeito de análise, considerou-se como solo característico SL, a média aritmética das frações do solo das 19 amostras.

No horto HA, foi coletado solo granular em jazida de cascalho. Foram coletadas amostras em vários pontos da cascalheira, formando-se uma amostra composta de cerca de $100 \mathrm{~kg}$ de cascalho. A amostra de cascalho foi designada como HA.

\section{Caracterização geotécnica}

As amostras de solo dos trechos rodoviários do horto SL e da jazida de cascalho do horto HA foram encaminhadas ao Laboratório de Geotecnia da Universidade de Brasília - UnB, no qual foram realizados os ensaios geotécnicos. Os seguintes procedimentos e ensaios foram realizados (Figura 2 e Figura 3):

\section{Preparação das amostras (ABNT NBR} 6457, 1984): secagem e homogeneização do solo SL e HA.

\section{Massa específica dos grãos de solo (ABNT} NBR 6508, 1984): com diâmetro menor que 2,0 mm para os solos SL e 4,8 para o solo HA;

$>\quad$ Granulometria completa (ABNT NBR 7181, 1984): peneiramento e sedimentação para os solos SL e HA. Foram comparados os resultados da sedimentação com e sem a utilização da solução defloculante de hexametafosfato de sódio nas amostras SL06 e SL16, selecionadas aleatoriamente, para verificação do grau de agregação das partículas em estado natural do solo SL.

$>\quad$ Limites de consistência (ABNT NBR 6459 1984; ABNT NBR 7180, 1984): limites de liquidez (LL), limite de plasticidade (LP) e índice de plasticidade (IP) para as amostras SL01, SL04, SL08, SL09 e SL14, selecionadas aleatoriamente. Essas amostras foram tomadas como característica do solo SL através da média aritmética dos valores encontrados.

$>$ Compactação de solos (ABNT NBR 7182, 1986): energias de compactação normal, intermediária e modificada para solo SL utilizandose o cilindro Proctor (pequeno). Para o solo HA, utilizaram-se as energias de compactação intermediária e modificada em cilindro CBR (grande);

$>\quad$ Resistência à Compressão Não Confinada - RCNC (BRASIL, 1994b): corpos de prova cilíndricos moldados nas energias de compactação normal, intermediária e modificada;

Índice de Suporte Califórnia - CBR (BRASIL, 1994a): $\mathrm{CBR}_{1 \text { ponto }}$ para o solo $\mathrm{SL}$ e $\mathrm{CBR}_{5}$ para o solo HA. Para os solos SL, o ensaio de CBR foi realizado para os dois melhores resultados dos ensaios de RCNC. 


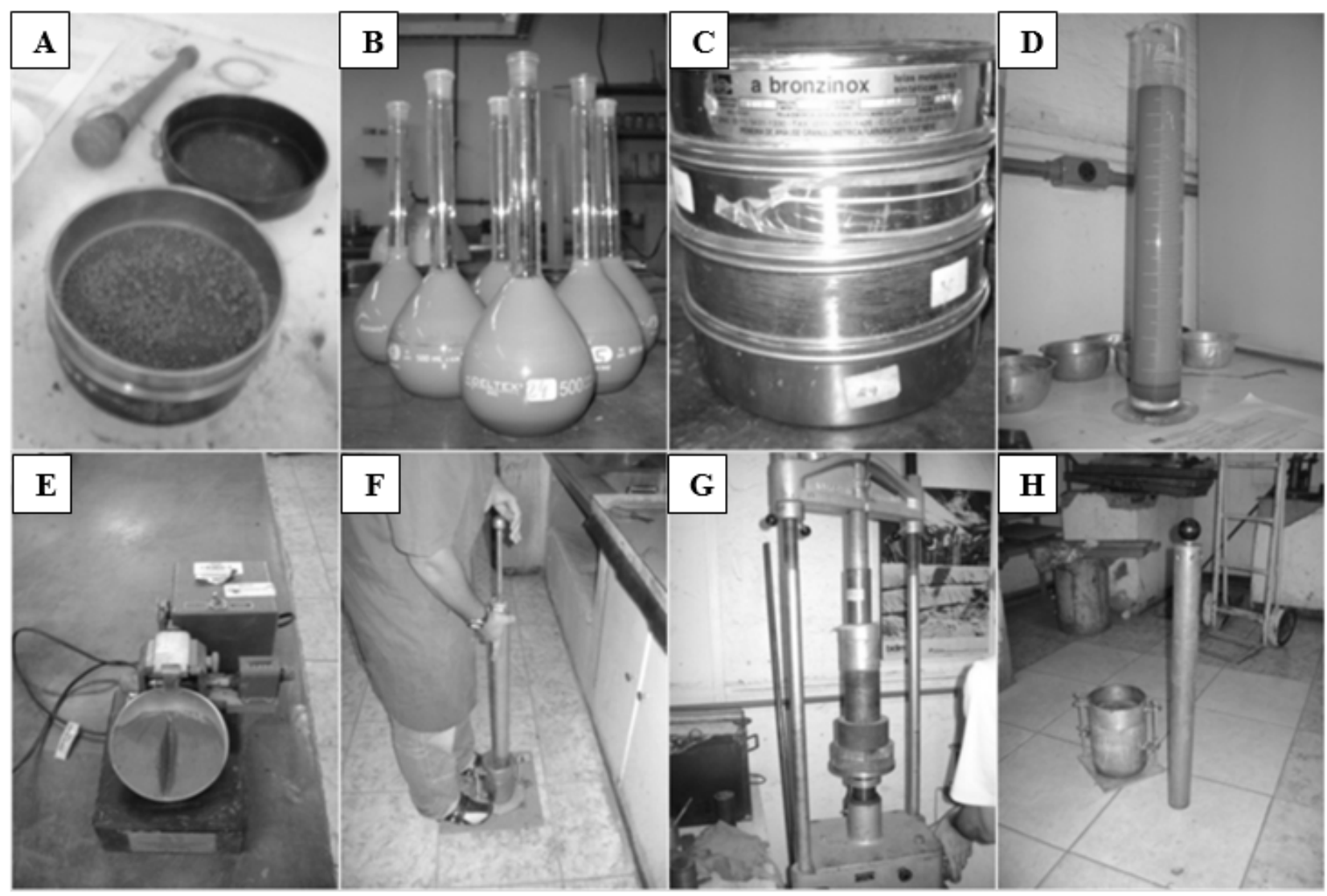

FIGURA 2: Procedimentos e ensaios geotécnicos: (A) Preparação de amostras; (B) Massa específica dos grãos; (C) Análise granulometria por peneiramento; (D) Análise granulométrica por sedimentação: (E) Consistência dos solos: limite de liquidez; (F) Compactação: cilindro proctor; $(\mathrm{G})$ Resistência à compressão não confinada; e (H) CBR: cilindro CBR e soquete de $4,5 \mathrm{~kg}$.

FIGURE 2: Procedures and geotechnical assays: (A) Preparation of samples; (B) Specific mass of the grains; (C) Particle size analysis by sieving; (D) Particle size analysis by sedimentation: (E) Consistency of soil: liquidity limit; (F) Compacting: proctor cylinder; (G) Compressive strength not confined; e (H) CBR: CBR cylinder and socket of $4,5 \mathrm{~kg}$.

\section{Classificação dos solos: TRB e MCT}

Para classificação pelo sistema rodoviário TRB (Transportation Research Board), utilizaramse as determinações de granulometria e os valores limites de consistência para as amostras SL01, SL04, SL08, SL09 e SL14. Em seguida, calculou-se o índice de grupo (IG), obtido conforme a equação (DAS, 2007):

$\mathrm{IG}=\left(\mathrm{F}_{200}-35\right)[02+0,005(\mathrm{LL}-40)]+0,01\left(\mathrm{~F}_{200}-15\right)(\mathrm{IP}-10)$ $\mathrm{IG}=\left(\mathrm{F}_{200}-35\right)[02+0,005(\mathrm{LL}-40)]+0,01\left(\mathrm{~F}_{200}-15\right)(\mathrm{IP}-10)$

Em que, $\mathrm{F}_{200}=$ Porcentagem que passa na peneira $\mathrm{N}^{\mathrm{0}} 200 ; \mathrm{LL}=$ Limite de liquidez; IP = Índice de plasticidade.
Realizaram-se, com as mesmas amostras, os ensaios para a classificação expedita MCT (Miniatura, Compactado, Tropical), mais apropriada para solos de regiões tropicais (Figura 4). Os grupos de solos MCT podem ser classificados como laterítico (L) ou não laterítico $(\mathrm{N})$ e as frações como argila $(\mathrm{G})$ ou argiloso (G'), siltoso (S') e areia (LA) ou arenoso (A') Empregou-se o método das pastilhas para identificação expedita do grupo MCT (NOGAMI; VILLIBOR, 1995).

Essa metodologia utilizada baseou-se na identificação e descrição expedita (visual-táctil) de solos, sendo realizados ensaios de contração e penetração. Com os resultados dos dois ensaios enquadra-se o solo no grupo MCT (Tabela 1). 


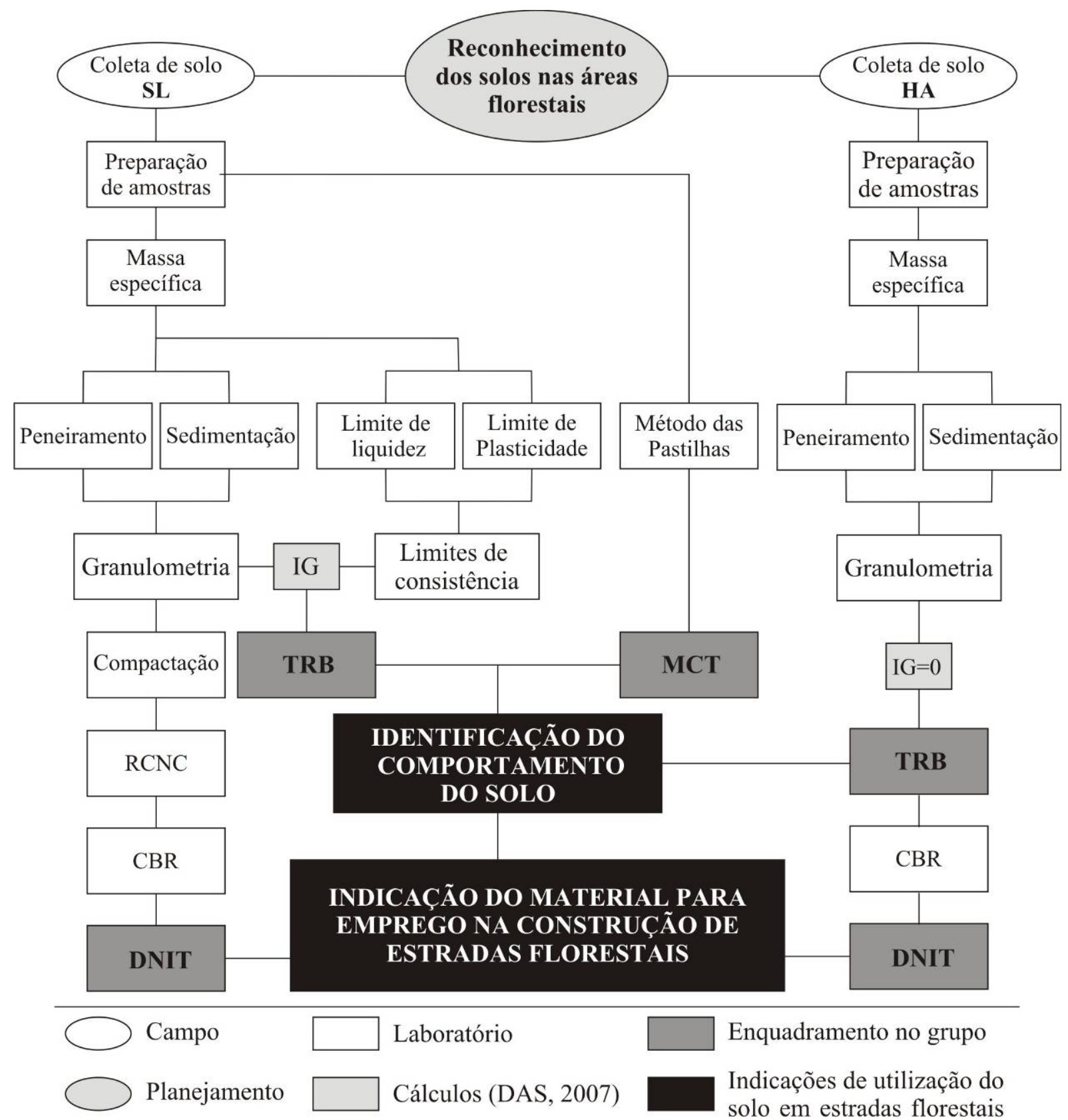

FIGURA 3: Matriz de procedimentos e ensaios geotécnicos.

FIGURE 3: Matrix of the procedures and geotechnical assays.

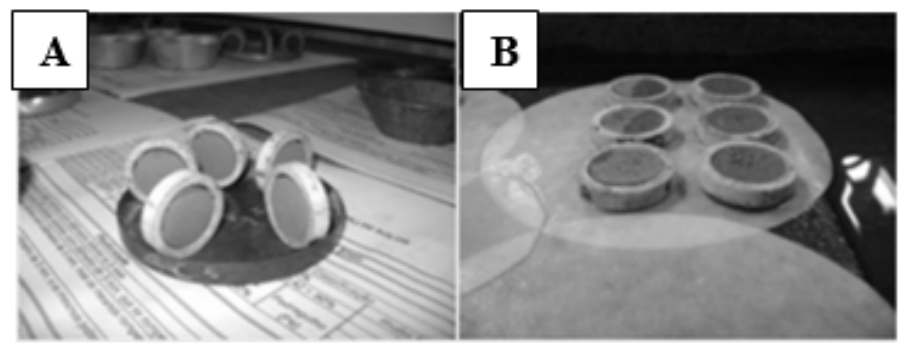

FIGURA 4: Método das pastilhas para identificação expedita do grupo MCT: (A) Ensaio de contração da pastilha; e (B) Ensaio de penetração;

FIGURE 4: Method of the tablets for fast identification of MCT group: (A) Assay of contraction of the tablet; e (B) Assay of penetration; 
TABELA 1: Classificação geotécnica de solos nos grupos MCT segundo a metodologia expedita.

TABLE 1: Geotechnical ground classification in groups MCT according to fast methodology

\begin{tabular}{|c|c|c|}
\hline \multicolumn{3}{|c|}{ Determinação do Grupo MCT } \\
\hline$c^{\prime 1}$ & Penetração (mm) & Grupo MCT \\
\hline \multirow{3}{*}{$<0,5$} & $<3,0$ & LA \\
\hline & 3,1 a 3,9 & NA \\
\hline & $>=4,0$ & NA / NS' \\
\hline \multirow{3}{*}{0,6 a 0,9} & $<2,0$ & LA - LA' \\
\hline & 2,1 a 3,9 & NA' - NS' \\
\hline & $>=4,0$ & NS' - NA' \\
\hline \multirow{3}{*}{1,0 a 1,3} & $<2,0$ & LA' $^{\prime}$ \\
\hline & 2,1 a 3,9 & NA' \\
\hline & $>=4,0$ & NS' \\
\hline \multirow{3}{*}{1,4 a 1,7} & $<2,0$ & $L^{\prime} A^{\prime}-\mathrm{LG}^{\prime}$ \\
\hline & 2,1 a 3,9 & NA' / NG' - NS' \\
\hline & $>=4,0$ & NS' - NG' \\
\hline \multirow{3}{*}{$>=1,8$} & $<2,0$ & LG' \\
\hline & 2,1 a 3,9 & NG' \\
\hline & $>=4,0$ & NG' \\
\hline
\end{tabular}

Em que: Os símbolos “_“ e “/” significam opção equivalente e opção decrescente, respectivamente.

${ }^{1}$ Contração total das pastilhas (ct): ct de 0,1 a $0,5 \mathrm{~mm}$, $\left.\mathrm{c}^{\prime}=(\log 10 \mathrm{ct}+1) / 0,904\right) ;$ ct $>0,6 \mathrm{~mm}, \mathrm{c}^{\prime}=(\log 10 \mathrm{ct}+$ $0,7) / 0,5$

Indicação do emprego dos solos como material rodoviário: DNIT

Com base nos resultados dos ensaios de CBR, classificaram-se os solos SL e HA como materiais construtivos, segundo o Departamento Nacional de Infraestrutura Terrestre - DNIT
(Tabela 2) (BRASIL, 2006).

\section{RESULTADOS E DISCUSSÃO}

\section{Massa específica e granulometria}

Na massa específica dos grãos dos solos finos, as amostras provenientes do horto florestal SL apresentaram média de $2,69 \mathrm{~g} / \mathrm{cm}^{3}$. A amostra de cascalho HA apresentou a massa específica dos grãos média (finos) de $2,85 \mathrm{~g} / \mathrm{cm}^{3}$.

Os resultados da análise granulométrica das amostras do solo SL mostraram uma predominância da fração areia fina, seguidas das frações de argila e silte, respectivamente. As exceções desta distribuição granulométrica foram encontradas nas amostras SL01 e SL08 com predominância da fração de argila, seguidas das frações de areia fina e silte, na amostra SL09, com predominância da fração de areia fina, seguidas das frações de argila e areia média, e nas amostras SL11 e SL12, com predominância da fração areia finas e percentuais muito próximos das frações silte e argila. Para caracterizar a granulometria (curva granulométrica), do solo SL, adotou-se a média dos diâmetros e das porcentagens das frações (Figura 5).

$\mathrm{Na}$ amostra de cascalho Ha, verificaram-se distribuições granulométricas com predominância da fração pedregulho médias, seguidas das frações pedregulho fino, pedregulho grosso, argila e areia fina, respectivamente (Figura 5).

Considerando os resultados do ensaio de sedimentação que determina as quantidades das frações finas do solo, foram comparadas amostras com e sem a utilização da solução defloculante de hexametafosfato de sódio, para verificar o estado de agregação das partículas de silte e argila no solo. O solo SL apresenta-se com textura arenosa em seu estado natural (sem defloculante), devido

TABELA 2: Adequação dos materiais empregados no pavimento rodoviário.

TABLE 2: Adequacy of the materials used in the road pavement.

\begin{tabular}{lccccc}
\hline \multicolumn{1}{c}{ Material } & Expansão (\%) & CBR (\%) & IG & LL (\%) & IP (\%) \\
\hline Subleito & $\leq 2 \%$ & $\geq 2 \%$ & - & - & - \\
Reforço de Subleito & $\leq 1 \%$ & $\geq 2 \%$ & - & - & - \\
Sub-base & $\leq 1 \%$ & $\geq 20 \%$ & 0 & - & - \\
Base & $\leq 0,5 \%$ & $\geq 80 \%$ & - & $\leq 25$ & $\leq 6$
\end{tabular}

Adaptado de Brasil (2006). Em que: $\mathrm{CBR}=$ Índice de suporte Califórnia; IG = İndice de grupo; LL = limite de liquidez; IP = Índice de plasticidade. 

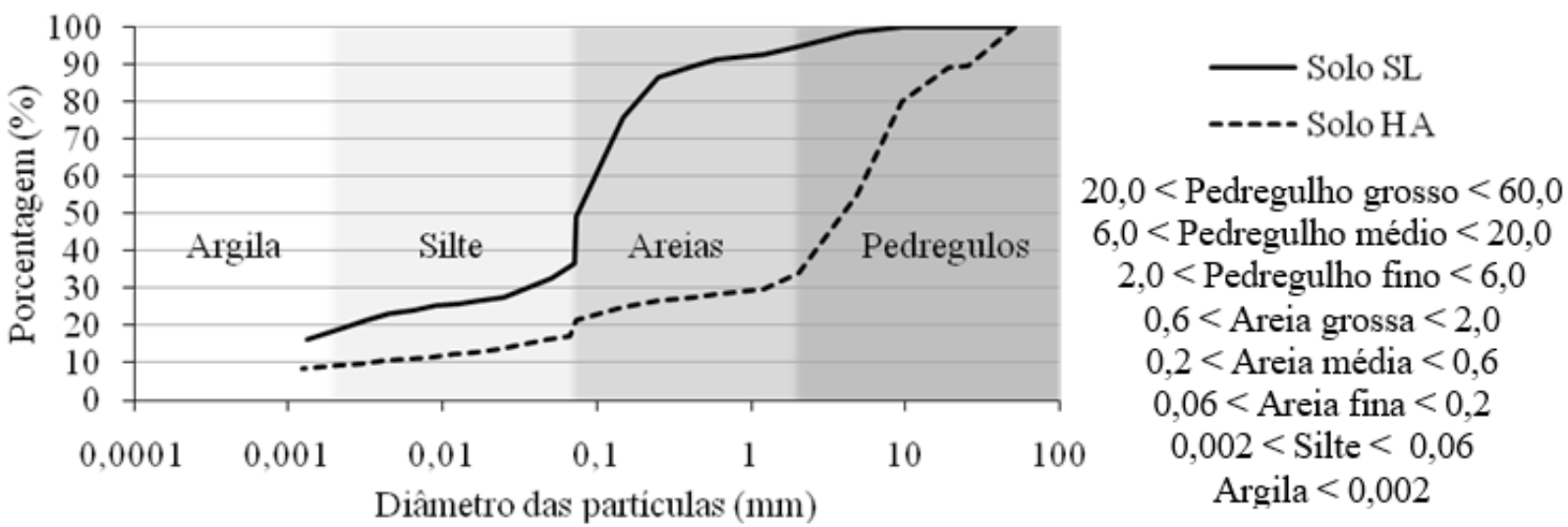

Faixas granulométricas conforme Norma Técnica da NBR ABNT 6502 (1995)

FIGURA 5: Curvas de distribuição granulométrica das amostras de solos SL (média) e HA. Sedimentação realizada com solução de hexametafostato de sódio.

FIGURE 5: Curves of grain sized distribution of the samples of SL (mean) and HA soils. Sedimentation carried through with solution of the hexametaphosphate of sodium.

à agregação das partículas de silte e argila, dando maiores dimensões às partículas finas do solo. No entanto, quando observado no ensaio de sedimentação com defloculante, as frações de silte e argila somaram em média $40 \%$ do total das frações (Figura 6).

\section{Limites de consistência}

Com base nos valores obtidos nos ensaios de limites de consistência, as umidades dos limites de liquidez e plasticidade demonstram características mais arenosas do solo SL, com valor médio de limite de liquidez e de plasticidade de $25,2 \%$ e $18,6 \%$, respectivamente. O índice de plasticidade também apresenta baixo valor (Tabela 3 ).

\section{Compactação}

A partir dos ensaios de compactação foram obtidos os parâmetros peso específico aparente seco máximo $\left(\mathrm{g}_{\text {dmáx }}\right)$ e a umidade ótima $\left(\mathrm{W}_{\mathrm{ot}}\right)$ (Tabela 4$)$. Os resultados são visualizados na forma de curva de compactação, apresentando o pico de peso

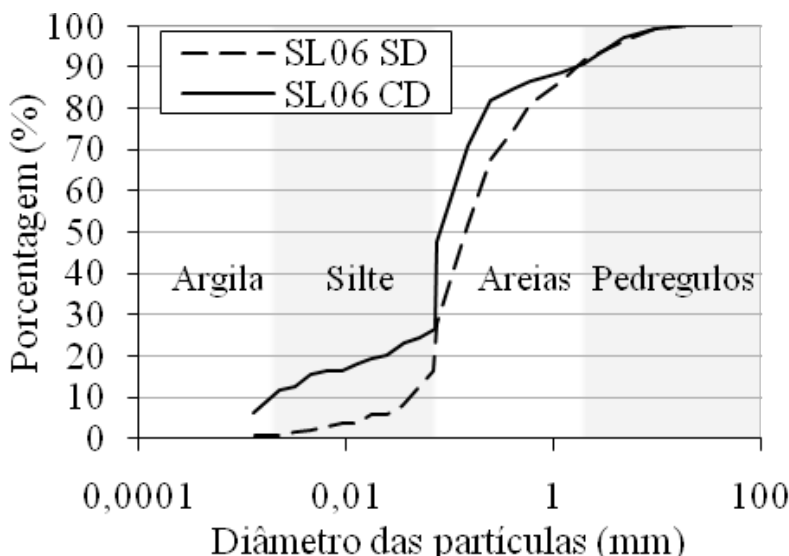

Em que: $\mathrm{SD}=$ sem defloculante; $\mathrm{CD}=$ com defloculante

FIGURA 6: Ensaio de sedimentação com e sem a utilização do defloculante: curvas granulométricas das amostras de solos SL06 e SL16.

FIGURE 6: Assay of sedimentation with and without the use of the defloculante: soil sized curves of sample soils SL06 and SL16. 
TABELA 3: Limites de consistência do solo SL.

TABLE 3: Limits of consistency of SL soil.

\begin{tabular}{ccccccc}
\hline \multirow{2}{*}{ Amostra } & \multicolumn{3}{c}{ Amostras Selecionadas } & \multicolumn{2}{c}{ Valores Médios Solo SL } \\
\cline { 2 - 6 } & LL (\%) & LP (\%) & IP (\%) & LL (\%) & LP (\%) & IP (\%) \\
\hline SL01 & 31,0 & 19,4 & 11,6 & & & \\
SL04 & 24,4 & 18,5 & 5,9 & & & \\
SL08 & 25,4 & 18,7 & 6,7 & 25,2 & 18,6 & \\
SL09 & 25,7 & 17,9 & 7,8 & & & \\
SL14 & 19,4 & 18,3 & 1,1 & & & \\
\hline
\end{tabular}

Em que: $L L=$ Limite de Liquidez; LP = Limite de Plasticidade; IP = Índice de Plasticidade

específico aparente seco máximo $\left(\mathrm{g}_{\text {dmáx }}\right)$ e a umidade ótima $\left(\mathrm{W}_{\mathrm{ot}}\right)$ correspondente. Para cada energia uma curva foi obtida, formando as famílias de curvas de compactação do solo SL (Figura 7).

TABELA 4: Parâmetros de compactação: peso específico aparente seco máximo $\left(\mathrm{g}_{\text {dmáx }}\right)$ e umidade ótima $\left(\mathrm{W}_{\mathrm{ot}}\right)$.

TABLE 4: Parameters of compacting: apparent specific weight dry maximum $\left(\mathrm{g}_{\text {dmáx }}\right)$ and excellent humidity $\left(\mathrm{W}_{\mathrm{o}}\right)$.

\begin{tabular}{ccccc}
\hline \multirow{2}{*}{$\begin{array}{c}\text { Parâmetros de } \\
\text { Compactação }\end{array}$} & \multicolumn{4}{c}{ Energia de Compactação } \\
\cline { 3 - 5 } & $\mathrm{N}$ & $\mathrm{I}$ & $\mathrm{M}$ \\
\hline $\mathrm{W}_{\mathrm{ot}}$ & $(\%)$ & 14,5 & 12,7 & 12,2 \\
$\gamma_{\text {dmáx }}$ & $\left(\mathrm{kN} / \mathrm{m}^{3}\right)$ & 17,947 & 18,614 & 19,418
\end{tabular}

Em que: $\mathrm{N}=$ energia normal; $\mathrm{I}=$ energia intermediária; $\mathrm{M}=$ energia modificada

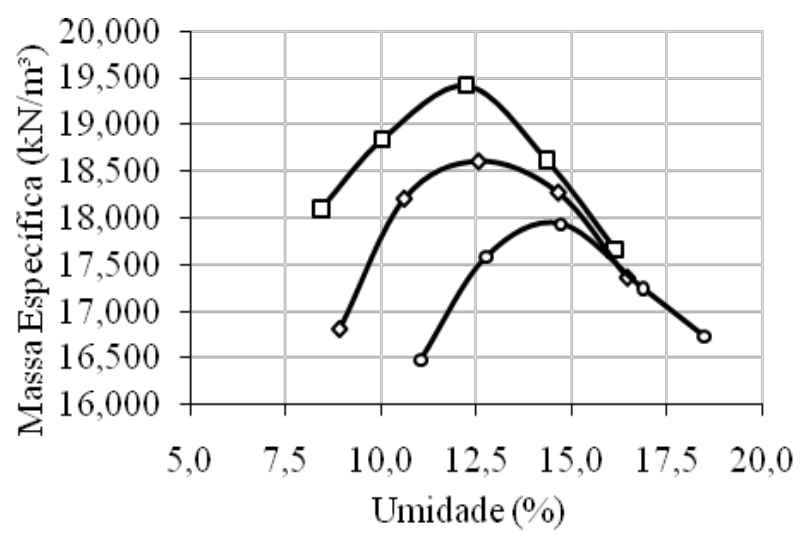

$\rightarrow$-Modificada $\leadsto$-Intermediária $\longrightarrow$ Normal

FIGURA 7: Família de curvas de compactação do solo SL (energia de compactação normal, intermediária e modificada).

FIGURE 7: The family of the SL soil compacting (energy of normal, intermediate and modified compacting).

Com base nos valores encontrados nos ensaios de compactação, quanto maior é a energia de compactação maior o peso específico máximo e menor a umidade ótima. O deslocamento mais acentuado na umidade ótima é visto quando comparadas as energias de compactação normal e intermediária, ou seja, há uma redução de 12,5\% na unidade. Entre as energias intermediária e modificada, a mudança no valor da unidade ótima é menos acentuada, decrescendo $4 \%$. Para os pesos específicos aparentes secos máximos alcançados, o aumento foi relativamente proporcional com o aumento da energia de compactação, cerca de $4 \%$ de elevação entre cada energia (Tabela 5).

TABELA 5: Variação percentual dos parâmetros de compactação em relação à energia de compactação.

TABLE 5: Percentage variation of the parameters of compacting in relation to the compacting energy

\begin{tabular}{cccc}
\hline Parâmetros de & \multicolumn{3}{c}{ Variação Percentual (\%) } \\
\cline { 2 - 4 } Compactação & $\mathrm{I} / \mathrm{N}$ & $\mathrm{M} / \mathrm{I}$ & $\mathrm{M} / \mathrm{N}$ \\
\hline $\mathrm{W}_{\mathrm{ot}}$ & $-12,5$ & $-4,0$ & $-15,9$ \\
$\gamma_{\text {dmáx }}$ & $+3,7$ & $+4,3$ & $+8,2$ \\
\hline
\end{tabular}

Em que: $\mathrm{N}=$ energia normal; $\mathrm{I}=$ energia intermediária; $\mathrm{M}=$ energia modificada

\section{Resistência Mecânica}

A partir dos parâmetros de compactação dos solos SL referentes às energias normal, intermediária e modificada, iniciaram-se os ensaios de compressão simples (RCNC) com a moldagem de três corpos de prova para cada energia de 
compactação, com variação de $0,5 \%$ para a umidade ótima $\left(\mathrm{W}_{\mathrm{ot}}\right)$ e $0,3 \%$ no grau de compactação, ou seja, no peso específico aparente seco máximo $\left(\mathrm{g}_{\mathrm{dmáx}}\right)$.

Nesse ensaio foram obtidos os parâmetros de resistência à compressão, índice de vazios e a relação de tensão e deformação para cada energia de compactação. Os valores dos parâmetros de RCNC foram calculados com base na média das três determinações (Tabela 6).

TABELA 6: Valores de Resistência a Compressão Simples (RCNC) médios nas diferentes energias de compactação.

TABLE 6: Values of Axial compressive strength (RCNC) average in the different energies of compacting.

\begin{tabular}{ccc}
\hline $\begin{array}{c}\text { Energia de } \\
\text { Compactação }\end{array}$ & Tensão $(\mathrm{kPa})$ & $\begin{array}{c}\text { Índice de } \\
\text { vazios }(\%)\end{array}$ \\
\hline Normal & 120,42 & 0,46 \\
Intermediária & 205,91 & 0,41 \\
Modificada & 385,10 & 0,36 \\
\hline
\end{tabular}

De acordo com as curvas médias de tensãodeformação, em ambas as energias de compactação, os corpos de prova tiveram uma deformação em relação a sua altura de $4 \%$ no momento da ruptura. $\mathrm{Na}$ energia de compactação modificada, a ruptura ocorre de forma mais acentuada, demonstrando o maior grau de agregação das partículas do solo (Figura 8). Durante os ensaios, os corpos de prova moldados nessa energia apresentaram ruptura longitudinal total e quebra abrupta.

Considerando as mesmas deformações, de $4 \%$ aproximadamente, camadas melhoradas de estradas florestais se construídas na energia de compactação modificada resistirão a cerca de 385,10 $\mathrm{kPa}$, deformando-se $4 \%$ de sua espessura. Tensões maiores causarão o rompimento e degradação mais grave do pavimento. Essa energia deve ser utilizada em casos de grande utilização do transporte florestal com alto escoamento de madeira, ou seja, tráfego intenso e extrapesado. Nessa energia, maiores quantidades de materiais devem ser utilizadas e de número de passadas dos rolos compactadores, resultando em elevação dos custos com a compra e transporte de materiais e hora/máquina.

\section{Capacidade de suporte e expansão}

A partir dos parâmetros de compactação

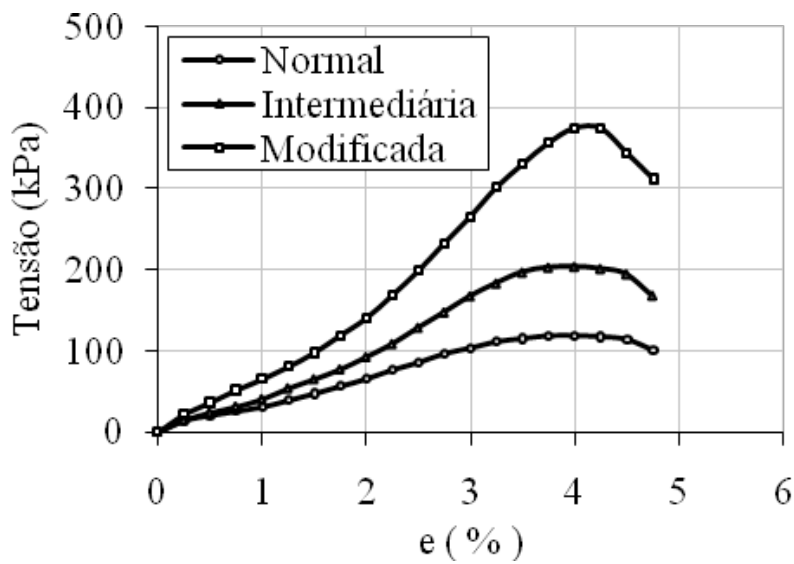

FIGURA 8: Curva tensão-deformação (Tensão de compressão versus deformação axial) dos valores médios das determinações de RCNC para cada energia de compactação.

FIGURE 8: Curve tension-deformation (Tension of compression versus axial deformation) of the average values of the determination of RCNC for each energy of compacting.

de e dos dois melhores resultados da resistência à compressão simples, iniciaram-se os ensaios de CBR nos solos SL. Três corpos de prova foram moldados no cilindro CBR para a determinação da expansão e da penetração, nas umidades ótimas $\left(\mathrm{W}_{\text {ot }}\right)$ e nos pesos específicos aparentes secos máximos $\left(\mathrm{g}_{\text {dmáx }}\right)$ das energias de compactação intermediaria e modificada, com variação permitida de $0,5 \%$ em relação à umidade ótima $\left(\mathrm{W}_{\mathrm{ot}}\right)$ e $0,3 \%$ no grau de compactação (Tabela 8).

O valor do índice de suporte foi maior na energia de compactação intermediária, contrariando o comportamento esperado, tendo em vista que quanto maior é a energia de compactação, maior será o peso específico, e teoricamente, maior seria a capacidade de suporte.

Para amostra de cascalho HA executouse o ensaio de $\mathrm{CBR}_{5 \text { pontos, }}$ com cinco corpos de prova compactados no cilindro $\mathrm{CBR}$ em diferentes umidades, conforme a norma do DNIT, para obtenção dos parâmetros umidade ótima $\left(\mathrm{W}_{\mathrm{ot}}\right)$ e pesos específicos secos máximos $\left(\mathrm{g}_{\mathrm{dmax}}\right)$. Empregaram-se as energias de compactação intermediária e modificada. Os cinco corpos de prova foram submetidos aos ensaios de expansão (imersão) e penetração, sendo os resultados destes ensaios, os valores observados nos pontos ótimos 
TABELA 7: Resultados dos ensaios de CBR para os solos SL e HA.

TABLE 7: Results of the assays of CBR for soils SL and HA.

\begin{tabular}{cccccc}
\hline \multirow{2}{*}{ Solo } & \multirow{2}{*}{ Energia de compactação } & \multicolumn{2}{c}{ Parâmetros de compactação } & \multicolumn{2}{c}{ Parâmetros de CBR } \\
\cline { 3 - 6 } & & $\mathrm{W}_{\mathrm{ot}}(\%)$ & $\gamma$ dmáx $\left(\mathrm{kN} / \mathrm{m}^{3}\right)$ & Expansão $(\%)$ & $\mathrm{CBR}(\%)$ \\
\hline \multirow{2}{*}{$\mathrm{SL}$} & Intermediária & 12,7 & 18,614 & 0,03 & 13,5 \\
& Modificada & 12,2 & 19,418 & 0,06 & 8,0 \\
\hline \multirow{2}{*}{$\mathrm{HA}$} & Intermediária & 14,5 & 18,848 & 0,03 & 59,3 \\
& Modificada & 10,3 & 19,507 & 0,12 & 94,9 \\
\hline
\end{tabular}

Em que: Wot = Umidade ótima; $\mathrm{CBR}=$ Indice de suporte Califórnia.

(umidade ótima e pesos específicos secos máximos) (Tabela 7).

\section{Classificação dos solos}

Segundo a metodologia expedita para a classificação dos solos no grupo MCT, as amostras do solo SL apresentaram características de solos laterítico (Tabela 8).

Com base nos resultados de granulometria e limites de consistência, os solos SL e HA, esse último apenas com resultados de granulometria, foram classificados de acordo com os grupos TRB (Tabela 9).

De acordo com as classificações estabelecidas para os solos, diferentes sistemas de classificação enquadram os mesmos materiais em categorias de materiais constituintes e comportamentos distintos. O solo SL, segundo a classificação TRB, enquadrou-se como material constituinte usual siltoso, enquanto que na MCT, o material foi areia argilosa. Com base na granulometria, areia fina e argila compõem 41,9 \%

TABELA 8: Resultados dos ensaios da metodologia expedita para identificação do grupo MCT do solo SL. TABLE 8: Results of the assays of the fast methodology for identification of group MCT of soil SL.

\begin{tabular}{|c|c|c|c|c|c|c|}
\hline \multirow{2}{*}{ Amostra } & \multicolumn{2}{|c|}{ Valor/Amostra } & \multirow{2}{*}{$\begin{array}{c}\text { Grupo MCT } \\
\text { Amostras }\end{array}$} & \multicolumn{2}{|c|}{ Valores Médios } & \multirow{2}{*}{ Grupo MCT Solo SL } \\
\hline & $\mathrm{c}^{\prime}(\mathrm{mm})$ & Penetração (mm) & & $c^{\prime}(\mathrm{mm})$ & Penetração (mm) & \\
\hline SL01 & 1,5 & 0,5 & $\mathrm{LA}^{\prime}$ - LG' & & & \\
\hline SL04 & 1,0 & 0,5 & LA' $^{\prime}$ & & & \\
\hline SL08 & 1,0 & 1 & LA' & 1,1 & 1,3 & LA' \\
\hline SL09 & 1,5 & 1 & LA' - LG' & & & \\
\hline SL14 & 0,5 & 3,5 & NA & & & \\
\hline
\end{tabular}

Em que: Para contração total (ct) entre 0,1 e $0,5 \mathrm{~mm}, \mathrm{c}^{\prime}=(\log 10 \mathrm{ct}+1) / 0,904$; Para contração total $(\mathrm{ct})>0,6 \mathrm{~mm}, \mathrm{c}^{\prime}$ $=(\log 10 \mathrm{ct}+0,7) / 0,5$.

TABELA 9: Classificação dos solos no grupo TRB.

TABLE 9: Classification of soils in group TRB.

\begin{tabular}{|c|c|c|c|c|c|c|c|c|c|c|c|c|}
\hline \multirow[b]{2}{*}{ Amostra } & \multicolumn{7}{|c|}{ Valor/Amostra } & \multicolumn{5}{|c|}{ Valores adotados para solo } \\
\hline & $\operatorname{LL}(\%)$ & IP (\%) & $\mathrm{F}_{10}$ & $\mathrm{~F}_{40}$ & $\mathrm{~F}_{200}$ & IG & Grupo TRB & LL (\%) & IP (\%) & $\mathrm{F}_{200}$ & IG & $\begin{array}{c}\text { Grupo } \\
\text { TRB }\end{array}$ \\
\hline SL01 & 31,0 & 11,6 & 96,9 & 93,1 & 67,8 & 6 & A-6(6) & & & & & \\
\hline SL04 & 24,4 & 5,9 & 97,4 & 92,5 & 51,2 & 0 & $A-4(0)$ & & & & & \\
\hline SL08 & 25,4 & 6,7 & 96,0 & 91,0 & 51,9 & 1 & A-4(1) & 25,2 & 6,6 & 52,7 & 1 & A-4(1) \\
\hline SL09 & 25,7 & 7,8 & 96,7 & 90,1 & 52,7 & 1 & $A-4(1)$ & & & & & \\
\hline SL14 & 19,4 & 1,1 & 96,0 & 88,3 & 39,8 & 0 & $A-4(0)$ & & & & & \\
\hline HA & - & - & 33,9 & 27,5 & 21,5 & 0 & A-1-b & - & - & 21,5 & 0 & A-1-b \\
\hline
\end{tabular}

Em que: $\mathrm{LL}=$ Limite de Liquidez; $\mathrm{IP}=$ Indice de Plasticidade; $\mathrm{F}_{10}=$ Porcentagem que passa na peneira $\mathrm{n}^{\mathrm{o}} 10 ; \mathrm{F}_{40}=$ Porcentagem que passa na peneira $\mathrm{n}^{\mathrm{o}} 40 ; \mathrm{F}_{200}=$ Porcentagem que passa na peneira $\mathrm{n}^{\mathrm{o}} 200 ; \mathrm{IG}=$ Índice de Grupo. 
TABELA 10: Classificação nos grupos TRB e MCT das amostras de solos SL e HA.

TABLE 10: Classification in groups TRB and MCT of the soils samples SL and HA.

\begin{tabular}{|c|c|c|c|c|c|c|c|c|c|}
\hline \multirow{3}{*}{ Solo } & \multicolumn{2}{|c|}{ Classificação } & \multicolumn{2}{|c|}{$\begin{array}{c}\text { Característica do grupo } \\
\text { TRB }\end{array}$} & \multicolumn{5}{|c|}{ Característica do grupo MCT } \\
\hline & \multirow[b]{2}{*}{ MCT } & \multirow[b]{2}{*}{ TRB } & \multirow[b]{2}{*}{ Material } & \multirow[b]{2}{*}{$\begin{array}{l}\text { Qualidade } \\
\text { geral como } \\
\text { subleito }\end{array}$} & \multirow[b]{2}{*}{ Material } & \multicolumn{4}{|c|}{ Ordem preferencial de uso } \\
\hline & & & & & & $\begin{array}{l}\text { Base } \\
\text { Vicinal }\end{array}$ & $\begin{array}{c}\text { Reforço } \\
\text { do } \\
\text { subleito }\end{array}$ & $\begin{array}{l}\text { Subleito } \\
\text { compactado }\end{array}$ & $\begin{array}{l}\text { Revestimento } \\
\text { primário }\end{array}$ \\
\hline SL & LA' $^{\prime}$ & A-4 (1) & $\begin{array}{l}\text { Solos } \\
\text { siltosos }\end{array}$ & Satisfatória & $\begin{array}{c}\text { Areias } \\
\text { argilosas }\end{array}$ & $1^{\mathrm{o}}$ & $1^{\circ}$ & $1^{\circ}$ & $1^{\circ}$ \\
\hline HA & - & A-1-b & $\begin{array}{l}\text { Fragmentos } \\
\text { de pedra, } \\
\text { pedregulho } \\
\text { e areia }\end{array}$ & Excelente & - & - & - & - & - \\
\hline
\end{tabular}

e $27,8 \%$, respectivamente, do total do solo SL, o indicado segundo a classificação MCT (Tabela 10).

O solo do horto florestal SL foi classificado como A-4(1) e LA' (arenoso laterítico), segundo as classificações TRB e MCT, respectivamente. $\mathrm{O}$ cascalho do horto florestal Ha, foi classificado segundo a TRB como A-1-b.

Conforme a classificação TRB, o solo apresenta comportamento "Regular a ruim" como material a ser empregado em subleitos rodoviários. Entretanto, os solos LA', de acordo com a classificação MCT, são de ordem preferencial de uso como material de base de estradas vicinais, reforço de subleito e subleito compactado. Os solos LA' apresentam facilidade de compactação e coesão adequada. Com base nessas características, as estradas florestais da empresa poderiam apresentar melhores padrões caso fossem devidamente compactadas, sem gastos onerosos, reduzindo custos com manutenção periódica de estradas, favorecendo ainda, o tráfego dos veículos de transporte (NOGAMI; VILLIBOR, 1981; NOGAMI; VILLIBOR, 2009).

Quando empregadas técnicas de estabilização química de solos, estudos realizados por Machado, Pereira e Pires (2003), em Latossolos de classificação TRB A-7-5(16), também de comportamento "Regular a mau", demonstraram que a adição do resíduo industrial grits apresentou ganhos potenciais em resistência mecânica apropriando suas características para aplicações em subleitos rodoviários, sendo potencialmente utilizável como agente estabilizante do solo para pavimentos de estradas. Outros estudos de estabilização de solos mostraram alterações em características geotécnicas requeridas em obras viárias, potencializando solos de mau comportamento, segundo a classificação TRB, como subleito de estradas florestais (PEREIRA; MACHADO; HARVALHO, 2006; TRINDADE et al., 2005).

\section{Classificação do material empregado no pavimento rodoviário}

De posse dos resultados de CBR, seguiram-se as recomendações do Brasil (2006) de classificação dos materiais empregados no pavimento rodoviário (Tabela 11).

TABELA 11: Classificação dos solos como material empregado no pavimento rodoviário.

TABLE 11: Classification of soils as material used in the pavement road.

\begin{tabular}{ccccc}
\hline Solo & $\begin{array}{c}\text { Energia de } \\
\text { compactação }\end{array}$ & $\begin{array}{c}\text { Expansão } \\
(\%)\end{array}$ & $\begin{array}{c}\text { CBR } \\
(\%)\end{array}$ & $\begin{array}{c}\text { Material } \\
\text { rodoviário }\end{array}$ \\
\hline SL & Intermediária & 0,03 & 13,5 & $\begin{array}{c}\text { Reforço de } \\
\text { Subleito }\end{array}$ \\
& Modificada & 0,06 & 8,0 & $\begin{array}{c}\text { Reforço de } \\
\text { Subleito }\end{array}$ \\
\hline HA & Intermediária & 0,03 & 59,3 & Sub-base \\
& Modificada & 0,12 & 94,9 & Base \\
\hline
\end{tabular}


Tendo como base a indicação de emprego do solo na infraestrutura rodoviária convencional, no âmbito florestal, a estrutura da estrada florestal apresenta-se como uma camada se solo natural e outra camada servindo como base (SESSIONS, 2007).

A camada natural refere-se ao subleito, sendo o solo SL, indicado para esse emprego. A camada base refere-se a uma camada melhorada ou revestimento primário utilizado para suportar diretamente o tráfego de veículos. De acordo com suas características, o solo HA apresenta-se como bom material para essa função

\section{CONCLUSÃO}

O solo fino SL apresentou predominância da fração de areia fina e baixa plasticidade. Em relação à resistência a compressão, quanto maior a energia de compactação maior a tensão suportada. Esse solo pertenceu aos grupos A-6(1) e LA' segundo as classificações TRB e MCT, respectivamente.

No solo granular, HA, a fração predominante foi a de pedregulho fino, classificando-se segundo o grupo TRB como A-1-b.

Os solos estudados apresentaram com comportamento satisfatório a excelente para aplicação em estradas florestais quando compactados corretamente, indicando o solo SL como subleito e o HA como base ou revestimento primário.

\section{AGRADECIMENTOS}

Ao CNPq pela concessão da bolsa de mestrado, à empresa Anglo American Ltda. por possibilitar o estudo em suas áreas florestais e ao Laboratório de Geotecnia da UnB.

\section{REFERÊNCIAS BIBLIOGRÁFICAS}

ASSOCIAÇÃO BRASILEIRA DE NORMAS TÉCNICAS. NBR 6457: Amostras de solos: preparação para ensaios de caracterização e compactação. Rio de Janeiro, 1984a. 9 p.

NBR 6459: Solo: determinação do limite de liquidez. Rio de Janeiro, 1984d. 6 p.

. NBR 6502: Rochas e solos. Rio de Janeiro, $1995.18 \mathrm{p}$.

. NBR 6508: Grãos de solos que passam na peneira 4,8 $\mathrm{mm}$ - determinação da massa específica.
Rio de Janeiro, 1984b. 8 p.

. NBR 7180: Solo: determinação do limite de plasticidade. Rio de Janeiro, 1984e. 3 p.

NBR 7181: Solo: análise granulométrica.

Rio de Janeiro, 1984c. 13 p.

NBR 7182: Solo: ensaio de compactação.

Rio de Janeiro, 1986. 10 p.

BRASIL. Departamento Nacional de Estradas De Rodagem. ME 049: Solos: determinação do Índice de Suporte Califórnia utilizando amostras não trabalhadas. Rio de Janeiro, 1994a. 12 p.

Departamento Nacional de Estradas De

Rodagem. ME 201/94: Solo-cimento: compressão axial de corpos-de-prova cilíndricos. Rio de Janeiro, 1994b. 4 p.

Departamento Nacional de Infraestrutura

de Transportes. Manual de Pavimentação. 3. ed. Rio de Janeiro: DNIT, 2006. 274 p.

BUENO, B. S.; VILAR, O. M. Mecânica dos solos. Viçosa: Universidade de Viçosa, 1980. 131p.

CARVALHO, J. B. Q. Fundamentos da mecânica dos solos. 2. ed. Campina Grande: Marcone, 2004. $310 \mathrm{p}$.

CASAGRANDE, A. Research on the Atterberg limits of soils. Public Roads, v. 13, n. 8, p. 121-136, 1932.

CRAIG, R. F. Soil mechanics. 2. ed. New York: Van Nostrand Runholds Company, 1980. 318 p.

DAS, B. M. Fundamentos da engenharia geotécnica. 6. ed. São Paulo: Thonson Learing, 2007. $561 \mathrm{p}$.

EMBRAPA. Sistema Brasileiro de Classificação de Solos. Brasília: Embrapa-SPI, 2013. 353 p.

IBGE. Diretoria de geociências. Mapa de clima do Brasil. Rio de Janeiro: IBGE, 2002. 1 mapa: 90x109 cm. Escala: 1:5.000.000.

KINNISON, C. S. A study of the Atterberg Plasticity Limits. Technologic Papers of Bureau Standards, Washington, n. 46, p. 3-18, 1915.

MACHADO, C. C.; PEREIRA, R. S.; PIRES, J. M. M. Influência do tratamento térmico do resíduo sólido industrial (Grits) na resistência mecânica de um latossolo para pavimentos de estradas florestais. Revista Árvore, Viçosa, v. 27, n. 4, p. 543-550, 2003.

MACHADO, C. C.; MALINOVSKI, J. R. Rede viária florestal. Curitiba: UFPR - Fundação de pesquisas florestais do Paraná. 1986. 157 p.

NOGAMI, J. S; VILLIBOR, D. F. Uma nova classificação de solos para finalidades rodoviárias. In: SIMPÓSIO BRASILEIRO DE SOLOS TROPICAIS EM ENGENHARIA, 1981. 
Anais... Rio de Janeiro: COPPE/UFRJ, 1981. p. 30-41. Pavimentação de baixo custo com solos lateríticos. São Paulo: Vilibor, 1995. 213 p.

Pavimentos econômicos: tecnologia do uso dos solos finos lateríticos. São Paulo: Arte \& Ciência, 2009. 782 p.

PEREIRA, R. S.; MACHADO, C. C.; HARVALHO, C.A. B. Uso de resíduos em pavimentos de estradas florestais: caracterização de solos e misturas solo-grits. Revista Árvore, Viçosa, v. 30, n. 4, p. $629-635,2006$.

ROAD RESEARCH LABORATORY. Mecânica dos Solos para Engenheiros Rodoviários. São Paulo: [s. n.], 1951.

SESSIONS, J. Forest road operations in the tropics. Oregon, USA: Springer, 2007. 170 p.

TRINDADE, T. P. et al. Compactação de solos: fundamentos teóricos e práticos. Viçosa: Editora UFV, 2008. $95 \mathrm{p}$.

TRINDADE, T. I. O. et al. Resistência mecânica de misturas solo-rbi grade 81. Revista Árvore, Viçosa, v. 29, n. 3, p. 413-418, 2005. 